\title{
Imagen y represión del «rojo- separatista». Algunos ejemplos de la izquierda catalana en 1939
}

\author{
Francesc Vilanova I Vila-Abadal *
}

\begin{abstract}
RESUMEN
La represión y la violencia políticas desatadas por los militares sublevados y sus cómplices civiles, a partir de verano de 1936, no solamente fue un aspecto ya previsto y programado de

la insurreción, sino que también se extendió por todo el territorio español y fue adaptado según las características de las diferentes regiones en donde se aplicó. En el caso de Cataluña, la represión franquista, además de aplicarse en sus líneas generales, añadió el plus del "separatismo", la persecución del catalanismo político y cultural en todas sus variantes posibles. De aquí que hiciera fortuna la expresión "rojo-separatista", tanto a nivel propagandístico como de acusación política y criminal, que permitia ensanchar la represión e incluir a un amplio número de víctimas: conservadores, republicanos, comunistas, católicos y

\section{ABSTRACT}

The political repression and violence launched by the rebel militaries and their civil accomplices, from the summer of 1936, was an aspect already foreseen and scheduled of the insurrection. Furthermore, this repression and violence was spread in the whole Spanish territory and adapted to the features of the features of the different regions where it was brought. In the case of Catalonia, the Francoist repression, besides of being applied in its general lines, added a plus of "separatism", the persecution of the political and cultural catalanism in any of its possible variants. From here it comes the expression "red-separatist" that become popular, both at the propaganda level, and to include in it a large number of victims: conservatives, republicans, communist, Catholics and freethinkers. The application of the
\end{abstract}

* Fundació Carles Pi i Sunyer y UAB. 
librepensadores. A partir del análisis de diferentes expedientes de responsabilidades políticas, puede seguirse la aplicación de la acusación de "rojo-separatista" y la construcción de una imagen muy concreta de los vencidos.

\section{PALABRAS CLAVE Franquismo. Represión. Catalanismo. Ventura Grassol. Joan Comorera. Marti Esteve. Marti Barrera. Ley de Responsabilidades Políticas. Republicanismo.}

charge of "red-separatist" could be followed from the analysis of different files of political responsibilities, which set up a very specific image of the ones defeated.

\section{KEYWORDS:}

Francoism. Repression. Catalanism. Ventura Grassol. Joan Comorera. Marti Esteve. Marti Barrera. Law of Political Responsibilities. Republicanism.

Maximiano García Venero (conocido en este mundo también como Tresgallo de Souza) tenía a gala haber elaborado y sintetizado la ecuación que resumía (y definía) el marco esencial en el que iba a moverse la represión que castigó con toda dureza la izquierda catalana en 1939. En uno de sus principales artículos de la guerra, Tresgallo de Souza ya recordaba que Falange «no se limita a señalar a los enemigos con la denominación de «rojos". Para nosotros es indispensable recalcar que estamos luchando contra los "rojo-separatistas". Separatistas de derecha y de izquierda. Un Carrasco y Formiguera y un Aguirre. Un Companys y un Leizaola" '. La asociación ya estaba hecha: católicos y gente de orden (pero catalanista) e izquierdistas (republicanos o comunistas). A partir de aquí, se ofrecía todo tipo de variantes de la fórmula y un amplio catálogo de características, en el que cabian extrañas alianzas entre anarquistas y separatistas, comunistas y católicos, frentes populares y masonería, bolchevismo internacional y nacionalismo. De todo ello se encargó Tresgallo de Souza de sistematizarlo en sus múltiples escritos:

[...] nos complacía la denominación de "rojos» que se aplicaba benévolamente a los componentes y defensores del Frente Popular. "Rojos" son los anarquistas y los marxistas y aun sus auxiliares republicanos. Pero entre los factores de la guerra trágica de estos meses, los separatistas tienen tanta responsabilidad como los «rojos".

"Creación. Las minorias nacionales españolas", Unidad (San Sebastián), 6-IV-37. Extractado en Josep Benet, L'intent franquista de genocidi cultural contra Catalunya, Barcelona, Publicacions de l'Abadia de Montserrat, 1995, p. 85. 
Los separatistas, auxiliados por los republicanos federalistas y autonomistas, hicieron posible el medro del marxismo y del anarquismo. Fueron los separatistas quienes dieron cauce a la corriente antipatriótica, que manaba de los decenios de liberalismo parlamentario.

[...] Era menester que el pueblo no olvidara la participación de los separatistas en la agonía de lo español, culminada en los cincos años de República.

Dimos, entonces, existencia al vocablo "rojos-separatistas". Este entraña la repulsa y la condenación hacia los bandoleros marxistas y anarquistas y hacia los separatistas catalanes y vascos... ${ }^{2}$.

Ciertamente, puede alegarse que Tresgallo de Souza era uno de los escritores falangistas más destacados por su demagogia españolista y sus delirios teóricos, pero no es menos cierto que era uno de los personajes con mayor audiencia literaria en los círculos del poder y su toma de posición hizo fortuna en la construcción del discurso franquista ${ }^{3}$.

Lo más importante de este ejemplo ( $y$ de otros que pueden aducirse) es que la fórmula trascendió el papel y se enquistó entre los criterios de represión fijados por los sublevados desde el momento en que las tropas franquistas pisasen suelo catalán. Cuando, a partir de enero de 1939, el aparato represivo se puso en marcha, la ecuación "rojo-separatista» se tradujo en una muy larga lista de nombres, entre los que habia los principales dirigentes políticos "rojos" y "separatistas". Más allá de los partidos y organizaciones perseguidos y prohibidos, las asociaciones de nombres dan una mejor idea acerca de como el binomio fue considerado como un todo, en el que ya no podian distinguirse sus elementos internos.

Disponemos de un ejemplo muy significativo acerca de como el discurso de la persecución a los "rojo-separatistas" se llevó a la práctica y abrazó a dirigentes efectivamente "rojos" (Joan Comorera, secretario general del Partit Socialista Unificat de Catalunya, PSUC) y a otros supuestamente «separatistas» (Marti Barrera i Ventura Gassol, d'Esquerra Republicana de Catalunya; i Martí Esteve, d'Acció Catalana Republicana). Estos personajes -y muchos otros, también «rojo-separatistas»- se vieron envueltos por la aplicación de la Ley de Responsabilidades Políticas de 9

\footnotetext{
2 "Creación. Los rojo-separatistas", Unidad (San Sebastián), 16-I-37 (Josep Benet, op. cit., pp. 85-86).

3 Que los planteamientos de Tresgallo de Souza habían sido bien recibidos y engarzados con otros elementos del discurso fascista (la conspiración judeo-masónica-comunista, el marxismo en todas sus variantes, el librepensamiento, etc.), era visible en los muchos articulos escritos en la zona franquista que daban vueltas a la misma fórmula y a sus combinaciones. Josep Benet, en su obra ya citada, ofrece numerosos ejemplos de como los argumentos de Tresgallo de Souza se reptien, en diferentes variantes, en este tipo de prensa.
} 
de febrero de 1939, que tenia particularidad de sancionar supuestos delitos políticos cometidos a partir del 1 de octubre de 1934, fecha-fetiche por excelencia en el imaginario franquista ${ }^{4}$. Era evidente que aplicando este principio de retroactividad, las nuevas autoridades franquistas iban a pasar factura a todos aquellos que, de una manera $u$ otra, protagonizaron los hechos del 6 de octubre de 1934 (proclamación del Estado Catalán por parte de Lluís Companys, President de la Generalitat, rompiendo el esquema constitucional vigente), además de otras consideraciones igual de relevantes (sus responsabilidades durante la guerra, etc.). Lo más interesante era la utilización del episodio de octubre de 1934 como elemento unificador para castigar/sancionar a políticos de trayectorías muy distintas, a la vez que mostraba como aquel episodio habia asumido un papel central en el discurso del franquismo con respecto a Catalunya y su pasado històrico inmediato 5 .

Terminada la guerra, pues, y puesta en marcha la máquina de la represión era el momento de revisar y castigar el pasado. Efectivamente, entre julio y septiembre de 1939 se abrieron una serie de expedientes de responsabilidades políticas que tenían en común un certificado del Tribunal Regional de Responsabilidades Políticas de Barcelona. Era la copia mecanografiada de la Orden de Presidencia, del 13 de octubre

4 Refiriéndome exclusivamente al ámbito catalán, empezamos a disponer de trabajos e investigaciones importantes sobre la aplicación de la Ley de Responsabilidades Políticas. Cabe destacar, sobre todo, el trabajo colectivo de Conxita Mir, Fabià Corretgé, Judit Farré i Joan Sagués, Repressió econòmica i franquisme: L'actuació del Tribunal de Responsabilitats Polítiques a la província de Lleida, Barcelona, Publicacions de l'Abadia de Montserrat, 1997. Otros trabajos de menor alcance, pero en la misma línea de investigación: Francesc Vilanova, "Les responsabilitats polítiques dels regionalistes catalans (1939-1942)", Recerques, núm. 31 (1995), pp. 19-36; Francesc Vilanova, "La Ley de Responsabilidades Políticas del 9 de febrer de 1939: un graó més de la repressió franquista", Perspectiva Social, núm. 38 (1996), pp. 39-53; Joan M. Thomàs, "Un aspecte de la repressió franquista a Altafulla: l'aplicació de la Ley de Responsabilidades Políticas", Estudis Altafullencs, núm. 22 (pp. 73-81); Joan M. Thomàs, "La repressió que no cessava", Kesse (Tarragona), núm. 24 (1997), pp. 20-23.

5 Hay numerosas muestras de como los hechos del 6 de octubre son utilizados para criminalizar el conjunto de la clase política republicana catalana, independientemente del papel que jugaran en él sus dirigentes. Uno de los mejores ejemplos, por su elaboración y planteamiento, es Julio Martínez Santa-Olalla ("La Universidad y el separatismo», Libertad. Diario Nacional-Sindicalista, 10-XI-38; recogido en Josep Benet, op. cit., pp. 55-56): “La Universidad va adquiriendo pujos europeos, es el momento de Ortega en que empieza a llevarse lo rubio, y con los fondos del Estado "centralista" — pues, desgraciadamente, esa única virtud del liberalismo no se ejercía- se va organizando de manera bastante inteligente —es de justicia reconocerlo- una dirección universitaria de todo el separatismo, que irradiando por el Institut d'Estudis Catalans, sociedades excursionistas, centros de lectura, museítos y ateneíllos, y sobre todo validos de la prepotencia de la Lliga, de la demagogia de la Esquerra más tarde y la hipocresía redomada del grupito del Matí, va infiltrándose en todas partes y llega a constituir el peligro que de manera bien clara se manifiesta el 6 de octubre de $1934 \ldots "$. 
de 1934, por la que eran cesados el gobierno de la Generalitat en pleno, con Lluís Companys al frente, y una larga relación de altos cargos de la administración catalana ${ }^{6}$. Era la consecuencia política diferida cinco años por los hechos de octubre de 1934. La Ley de Responsabilidades Políticas habia fijado la retroactividad de su aplicación teniendo en cuenta dos escenarios muy concretos: la revolución asturiana y el 6 de octubre catalán. Para Cataluña, además la Ley contemplaba la posibilidad -llevada a la práctica en otros expedientes- de sancionar a personajes políticos moderados que, por razón de su cargo público en aquellas fechas, se vieron implicados, a su pesar, en los hechos del octubre catalán ${ }^{\text {? }}$. Ello daba una amplitud a la represión política y, sobre todo, era una advertencia para aquellos sectores sociales moderados (conservadores, republicanos o no) que no acababan de lanzarse abiertamente en brazos del franquismo, que no habian hecho pública su "adhesión inquebrantable" al nuevo régimen ${ }^{8}$.

Pero más allá de la aplicación casi universal de la Ley en el ámbito general del catalanismo político ${ }^{9}$, el objetivo principal del franquismo triunfante era cobrarse una larga y abultada factura con los directos responsables

6 Los nombrados en el decreto y, por lo tanto, susceptibles de padecer un expediente de responsabilidades politicas (no todos pasaron por este trámite) eran: Lluís Companys, Joan Lluhí i Vallescà, Josep Dencàs, Martí Esteve, Ventura Gassol, Martí Barrera, Joan Comorera, Pere Mestres, Josep Puig Pujades, Pere Valldeoriola Andreu, Lluís Prunés, Josep Irla, Joan Tauler, Josep M. Espanya, Amadeu Oliva, Jaume Marti, Josep Tarragona, Pere Coll, Joan Ricart i Jesús Pérez Salas.

Uno de los casos más emblemáticos fue el del concejal del Ayuntamiento de Barcelona, Estanislau Duran i Reynals, un republicano moderado (adscrito a Acció Catalana Republicana), con una trayectoria política discreta (era abogado de profesión y ejercía como tal), un burgués ilustrado que rompió con su pasado republicano en 1936, a quien se le abrió un expediente por ocupar un sillón en el ayuntamiento en aquellas fechas, aunque no tuvo ninguna intervención personal en el episodio y se manifestó abiertamente en contra.

8 Desde la zona franquista, se había advertido que todo el mundo catalanista, desde la Lliga Catalana hasta Unió Democràtica de Catalunya, pasando por Esquerra Republicana, tendría que rendir cuentas, más allá de lo sucedido durante la guerra en el territorio catalán: “...Desde los sectarios de la Esquerra hasta los católicos de la Unión Democrática de Catalunya [sic], todos los que se han aliado con el marxismo bolchevique, con los republicanos del Frente Popular y con los anarcosindicalistas en la criminal faena de arruinar y destrozar a España, rendirán tributo a la justicia o huirán en tropel al extranjero..." (Enrique de Angulo, "Catalanismo a la hora de la victoria. Cataluña ante la nueva España", Domingo, 13-V-38; recogido en Josep Benet, op. cit., p. 179).

9 Y no solamente para este ámbito. Vale la pena tener en cuenta que se abrió un expediente de responsabilidades políticas a Carlos Godó Valls, conde de Godó, propietario de La Vanguardia Española y uno de los franquistas más relevantes del momento. Otro caso llamativo fue el del pintor Pere Pruna, artista de ideas derechistas antes de la guerra y pintor casi oficial de la burguesía franquista de posguerra. Aunque los motivos que provocaron el inicio de estos expedientes no tienen nada que ver con el episodio de octubre de 1934, el solo hecho de que se les aplicara la Ley a estos personajes ya es un síntoma inquietante de la dinámica que había tomado la represión política franquista y su alcance. 
de los hechos de octubre de 1934 y, por extensión, los directores de la política pública catalana durante la década de los años treinta. Además, existían otras previsiones: las autoridades franquistas disponían de otras armas represivas que complementaban la persecución política. La aplicación de la Ley de Responsabilidades Políticas era sólo un aspecto más de un programa mucho más amplio, que descansaba en el Código de Justicia Militar, los decretos de depuración de los colegios profesionales (abogados, arquitectos, médicos...) y toda la legislación paralela acerca de crímenes, robos, saqueos, incautaciones, militancias políticas, etc., que se habia generado en la zona franquista durante los tres años de guerra.

Del amplio grupo de políticos encartados en la Ley de Responsabilidades, y conectados entre ellos por el común denominador del 6 de octubre de 1934 , he seleccionado a cuatro, representativos de tres de las principales organizaciones políticas catalanas del período republicano: Ventura Gassol (Estat Català y Esquerra Republicana de Catalunya), Martí Esteve (Acció Catalana Republicana), Martí Barrera (ERC) ${ }^{10}$ y Joan Comorera (primero en la Unió Socialista de Catalunya y, a partir de 1936, secretario general del PSUC). Mientras los tres primeros caerian de lleno dentro del "separatismo" (con la derivación anarquista en el caso de Martí Barrera), Comorera es el elemento «rojo»; la común condición de consejeros de la Generalitat en 1934 -y en etapas posteriores- da sentido a la combinación «rojo-separatistas».

Según establecía la Ley de Responsabilidades Políticas, los expedientes debían construirse a partir de las aportaciones de los informes oficiales (Ayuntamiento, Policia, Guardia Civil, Falange y Cura-Párroco), además de las averiguaciones en las instituciones financieras acerca de la solvencia econòmica del inculpado. Teniendo en cuenta que la Ley tenía una clara vocación confiscatoria, este último aspecto era muy importante. Del conjunto del material aportado al expediente, el juez instructor elaboraba un resumen conclusivo y lo trasladaba al Tribunal Regional, encargado de dictar sentencia.

El primero del grupo a pasar por el Tribunal Regional de Barcelona fue Ventura Gassol, poeta, ex-seminarista, fiel escudero político de Francesc Macià ya en los años veinte, Consejero de Cultura de la Generalitat, de forma casi ininterrumpida entre 1931 y 1936 (con el paréntesis forzoso de

10 Marti Barrera, ex-Consejero de Trabajo de la Generalitat tenía otra particularidad añadida, que permite integrar una nueva dimensión a la combinatoria "rojo-separatista": su antigua militancia en la CNT, lo que le permitió conservar excelentes relaciones con el mundo anarco-sindicalista mientras ocupó el cargo de Consejero de Trabajo. En este caso, la combinación era triple (algo que también contemplaba el imaginario franquista): "rojo-separatista-anarquista" o las variantes del tipo «anarco- comunismo-separatismo". 
octubre de 1934 a marzo de 1936). Desde de la óptica franquista, Gassol era el "rostro" del 6 de octubre y, por extensión, del separatismo catalán en su conjunto. Sin embargo, el expediente se inició por el motivo, genérico, de ser "ex-Consejero de la Generalidad de Cataluña». Si tenemos en cuenta que Gassol habia ocupado este cargo durante los años cruciales de la República, y los primeros meses de la guerra, era fácil imaginar que el inculpado reunía todas las condiciones que la Ley había previsto para abrirle un expediente.

La primera parte del expediente está dedicada a las investigaciones acerca del patrimonio económico de Ventura Gassol. Como ni éste, ni ningún familiar, habia presentado la obligada declaración jurada de bienes por razones obvias, tuvo que ser la Guardia Civil quien le localizase dos cuentas corrientes en la Caja de Ahorros, con un valor total de 957 pesetas ${ }^{11}$. Gassol ya no era insolvente, por lo que, según la Ley, podían continuar los trámites para la confiscación de sus bienes y la aplicación de la sanción política correspondiente.

Hecho este primer paso, empezaron a llegar los informes oficiales preceptivos. Tratándose de un personaje político de primera fila, las autoridades franquistas de todos los ramos coincidieron en que no era necesario matizar ni contrastar la información; dicho de otra forma, no había razón para controlar la demagogia propia de los vencedores. Lo que había sido publicado en la prensa franquista durante la guerra (y en la prensa española de derechas de antes) tendría ahora su continuación lógica en el expediente. Los primeros en marcar la pauta fueron los funcionarios del Instituto Municipal de Estadística de Barcelona. Para empezar, la actuación de Gassol antes de la sublevación militar de julio de 1936 había sido "malísima»; durante el Glorioso Movimiento Nacional, su actitud no admetía paliativos: "Hombre cobarde y propagandista acérrimo. [...] Gran traidor a la Patria". Los últimos puntos del informe terminaban por poner las cosas en su sitio. A la pregunta "Voluntario o forzoso en las filas rojas", la respuesta: "No, por ser dirigente y cobarde». A la última pregunta, "Su libertad significaría peligro para el Glorioso Movimiento Nacional, o sería perniciosa por falta de ejemplaridad", los funcionarios contes-

11 El 30 de agosto de 1939, la policia barcelonesa comunicaba la localización de un depósi. to en el Banco Hispano-Colonial y una finca en la Rambla del Carmelo, a nombre de Maria Pujol Tura, "madre de la concubina del informado". En dicha finca se guardaban «muebles, libros y efectos propiedad del inculpado". El 22 de noviembre de 1939, el Rondín Antimarxista (dependiente de la Jefatura Superior de Policía de Barcelona, pero con una gran autonomía de actuación) informaba que habia encontrado, en la finca de la Rambla del Carmel, "abundante información perteneciente a dicho ex-consejero". 
taron con un escueto (y contundente) "Sí». Llegados a este punto, cabe señalar que ya no se trataba de algún periodista iluminado de Valladolid o Burgos que, en plena euforia bélica, se hubiese lanzado por los caminos de la demagogia más salvaje; no eran los jefes de Falange, ni los máximos dirigentes de la dictadura triunfante. Eran unos funcionarios municipales de Barcelona, que habian rellenado un cuestionario impreso, firmado finalmente por el alcalde de la ciudad, Miquel Mateu i Pla. Los protagonistas de la represión, los ejecutores de las directrices del poder franquista, no siempre llegaban de fuera de Cataluña. Algunos catalanes, de cualquier condición social y profesional, en 1936 se creyeron vencidos; ahora, en 1939, se sentian vencedores y actuaban como tales ${ }^{12}$.

El ayuntamiento de Barcelona había situado el listón en un nivel muy alto. A partir de aquel momento habría que ver si el resto de informes oficiales mantendrian el nivel. De momento, el informe de la Falange local era sorprendentemente seco y objetivo (siempre dentro de los parámetros falangistas). El repaso al historial político de Ventura Gassol sólo recogía los tópicos habituales: participante en el "complot separatista» de Prats de Molló y en «la intentona revolucionario-separatista" del 6 de octubre de 1934. Y poca cosa más. Ni «cobarde», ni «gran traidor». Era un informe poco falangista.

Todos los comentarios y adjetivos que se habian ahorrado los falangistas, fueron utilizados con profusión en la Jefatura Superior de Policía de Barcelona. Para empezar, los funcionarios policiales habian encontrado problemas de moralidad, pública y privada: «dicho individuo ha observado mala conducta moral pública y privada, habiendo vivido en unión de una mujer a la que hacía pasar por su esposa, ignorándose si últimamente contrajo matrimonio con ella». Planteadas las dudas sobre la moralidad del personaje, ahora le tocaba el turno a la política. Gassol "se ha distinguido siempre por su acendrado separatismo, siendo el amante [sic] de Estat Catalá" y fundador de Esquerra Republicana de Catalunya. Hizo campañas separatistas por América en los años veinte

12 Conxita Mir, Fabià Corretgé, Judit Farré, Joan Sagués, op. cit., pp. 180-201, ofrecen una amplia panorámica acerca del papel de vecinos e instituciones locales en la denuncia y la tramitación de los expedientes de responsabilidades políticas en la provincia de Lleida. Véase, también, Jaume Fabre, "La delació dins la repressió franquista de postguerra", L'Avenç, núm. 75 (1984), pp. 30-39. En el expediente contra los médicos Joaquim i Antoni Trias Pujol, tienen un papel muy destacado antiguos colegas suyos de la Facultad de Medicina de la Universidad de Barcelona y del Hospital Clínico. En el caso de Josep Queralt, fundador de Edicions Proa (una de las editoriales catalanas más importantes antes de la guerra), los testimonis desfavorables de dos vecinos de localidad fueron determinantes para establecer las sanciones. En el expediente contra Camil Companys, hermano del presidente de la Generalitat, el detonante fue la comunicación/denuncia del Colegio de Abogados de Barcelona acerca de su depuración como colegiado en diciembre de 1939. 
y en todas sus poesias "siempre hablaba de Cataluña como patria independiente" "13. Se le consideraba "culpable directo del advenimiento de la República del 31" y estuvo "encartado en la criminal revolución anarco-separatista de octubre del 34». Fue uno de los organizadores de la campaña electoral del Frente Popular (en Cataluña recibió el nombre de Front d'Esquerres, pero la policia no estaba para sutilezas) y ocupó el cargo de "Consejero de la extinguida Generalidad" durante "la dominación rojo-separatista". Éste sí que era un informe oficial que cumplía los requisitos esperados y era coherente con la literatura franquista del momento. Estaban todos los elementos que debian encontrarse en estos casos: una conducta moral dudosa, una trayectoria política abominable ${ }^{14}$.

Pero la policia de Barcelona no había terminado su trabajo. En una actuación poco habitual, diez días después del primer informe, hizo llegar un segundo informe al juez instructor. Esta vez, el origen era el Jefe Inspector de la Brigada Social y el contenido era mucho más rico y contundente. Vale la pena leerlo en su integridad:

Poco antes del advenimiento de la República, vino a España con Maciá y otros elementos de la "Esquerra", dedicándose todos ellos a promover huelgas y desmanes para provocar la caída de la Monarquía, no cejando en sus actividades nefastas hasta que se implantó la República, siendo entonces nombrado Consejero de Cultura de la Generalidad, en cuyo departamento hizo obra marcadamente separatista. Más tarde fue nombrado Diputado a Cortes y del Parlamento de catalán, resaltando en ambos Parlamentos poco su labor, por sus escasas actitudes de orador, pero nefasta por su enconado antiespañolismo; fue de los principales responsables de los hechos del 6 de Octubre, haciendo aquella noche varias llamadas por radio, invitando a los extremistas a que volaran puentes y tomasen las armas para defender el Estado catalán recientemente proclamado.

En las elecciones de febrero del 36 fue reelegido Diputado y repuesto en su cargo de Consejero de la Generalidad, en donde continuó su obra separatista; en el 19 de julio, como en el 6 de octubre, se distinguió por sus exaltadas arengas por radio, invitando a las hordas demandados a la destrucción de bienes y ataques a personas de orden; en uno de sus discursos atacó al

13 Ciertamente, Gassol era conocido como un poeta neorromántico, autor de versos muy patrióticos. Su libro Les tombes flamejants fue el paradigma de la poesía nacionalista catalana anterior a la guerra civil.

14 La, llamémosla asi, riqueza de contenidos de los informes de la policía barcelonesa en estos expedientes puede relacionarse con el hecho de que, posiblemente, los funcionarios de la policia que los redactaron ya estaban en activo, en Barcelona, durante la República. Sólo así pueden entenderse algunas noticias muy concretas acerca de las actividades de los politicos republicanos catalanes; funcionarios trasladados a la capital catalana al final de la guerra no habrían podido redactar informes tan completos, aunque sí igual de manipulados y sesgados. 
Obispo de Barcelona, Dr. Irurita, que luego fue asesinado. En dicho discurso dijo Gassols [sic] que donde lo encontraran habia que matarlo, por lo que cabe considerarle como principal responsable de dicho asesinato.

Cuando, luego la F.A.I, desbordando a la sombra del Gobierno catalán, actuó en pleno régimen anárquico, y los gobiernos rojos trataron de aniquilarla, de que se enteraron los anarquistas, estos iniciaron un ataque a fondo a la "Esquerra", "Estat Catalá» y demás partidos políticos gubernamentales, cuyos directivos, gobernantes y afiliados destacados tuvieron que huir para salvar sus vidas en grave peligro, diendo de este de quien relatan en toda la España la regocijante anécdota de que apenas puso el pie en Francia cantó la primera estrofa de la oda catalana "El Emigrant», cambiando el último verso, que en el canto auténtico es "anyoranca es mort" [sic] por el de “renoi quina sort».

Parece ser que Gassols [sic] recibió enseñanza religiosa y que había sido creyente, pero por la política renegó de todo. En Francia huido le dieron el cargo de Agente de Compras de Material bélico para el Ejército rojo, en cuyas operaciones comerciales parece obtuvo mucho dinero que es el que en la actualidad tiene fuera de España. Aquí no se le conocen bienes particulares.

Aquí sí que aparecen todos los elementos literarios sobre los que se construyó el discurso franquista de la represión contra el mundo catalanista. Al lado de comentarios más o menos insultantes hacia la persona de Ventura Gassol, la Brigada Social de Barcelona apuntaba e incriminaba sobre hechos muy concretos: la responsabilidad de Gassol en los hechos del 6 de octubre de 1934; la responsabilidad en el supuesto asesinato del obispo Irurita; el enriquecimiento con operaciones comerciales poco confesables en el extranjero. El informe servía para subir el nivel del expediente y para concretar, al fin, el retrato de uno de los personajes republicanos más odiados por los vencedores.

El centro de todas las pruebas y documentos aportados al expediente era el episodio del 6 de octubre de 1934. Y era asi no solamente por el carácter simbólico-político de aquellos hechos, sino también porque existían un proceso y unas condenas contra los principales protagonistas. Como se hizo con los otros implicados, las autoridades franquistas rescataron los expedientes policiales de 1934 y 1935, en donde se hacía constar las condenas por el delito de «rebelión militar». Los papeles eran un conjunto de copias mecanografiadas de los documentos originales, que se habían conservado en los expedientes personales: los traslados del barco-prisión Uruguay a Madrid para ser juzgado por el Tribunal de Garantías Constitucionales, los procedimientos de responsabilidades civiles, la sentencia condenando a Ventura Gassol a treinta años de prisión, etc. El conjunto era una muestra del gran interés del franquismo para fundamentar sus propias 
acusaciones de 1939 y para situar el 6 de octubre de 1934 como el núcleo duro del conjunto de responsabilidades políticas que se dilucidaban en el verano de 1939.

Aunque la Ley contemplaba otros trámites (faltaba, por ejemplo, el informe eclesiástico que, cuando llegó, sólo contenía una línea considerando a Ventura Gassol un «desconocido»), el juez instructor cerró el expediente en este punto.

El 7 de diciembre de 1939, los magistrados del Tribunal Regional de Barcelona tomaron en consideración el informe de la Brigada Social de Barcelona en su integridad y lo incorporaron a la sentencia. El resultado no podía ser otro que la aplicación de las sanciones máximas establecidas por la Ley: la pérdida total de bienes, la inhabilitación absoluta perpetua para ejercer cargos públicos, el destierro y la propuesta de pérdida de la nacionalidad española ${ }^{15}$.

El siguiente "hombre del 6 de octubre" que pasó por el Tribunal Regional fue Martí Esteve i Guau, dirigente de Acció Catalana Republicana y Consejero de la Generalitat. Enseguida se observa que Martí Esteve tenía un valor añadido para los franquistas, en la medida que había sido una de las piezas claves en todas las transacciones económicas que la Generalitat había hecho en el extranjero durante la guerra civil. Con dinero por el medio, los inculpados siempre eran más interesantes.

15 El resumen sobre la trayectoria política de Ventura Gassol, redactado para la sentencia, era muy similar a los textos de la policia barcelonesa, aunque cargando las tintas por el lado separatista: "...es uno de los elementos destacados como separatistas de izquierda, militante del Estat Catalá, íntimo amigo de Maciá, fue provocador de huelgas y disturbios contra la monarquia y al implantarse la República, una vez concedido el Estatuto a Cataluña fue designado Consejero de Cultura de la Generalidad, cargó que aprovechó para sus tines separatistas. Fue elegido Diputado a Cortes y del Parlamento catalán, siendo sus intervenciones netamente antiespañolas. De. sempeñaba el cargo citado el día 6 de octubre de 1934, y fue de los que llamó al pueblo contra España, incitando a las masas a defender el estado catalán recién proclamado. En las elecciones de febrero de 1936 fue elegido Diputado y repuesto en el cargo siguió como Consejero haciendo campaña separatista. El dia 19 de julio de 1939 [sic], se dirigió por radio, incitando a las masas contra las personas de orden entre ellas el Obispo Sr. Irurita que luego fue vilmente asesinado al triunfar momentaneamente la horda roja. Al gobernar de hecho la F.A.l., huyó al extranjero, actuando como agente de compras del Gobierno rojo, habiéndose quedado como medio dinero del destinado a la compra de material de guerra". Si existian "separatistas de izquierda" (la inevitable combinación "rojo-separatista"), también tenían que existir "separatistas de derecha", lo que explica, en parte, los expedientes de responsabilidades politicas de algunos dirigentes destacados de Lliga Catalana (Lluís Duran i Ventosa, Felip Rodés, Raimon d'Abadal...); véase Francesc Vilanova, "Les responsabilitats polítiques dels regionalistes catalans (1939-1942)", ya citado; para los casos concretos de Raimon d'Abadal i Calderó (presidente de la Lliga) y Ramon d'Abadal i de Vinyals (director de su periódico, La Veu de Catalunya), véase también, Francesc Vilanova, Ramon d'Abadal: entre la história i la política, Lleida, Pagès editors, 1996. 
A parte de incorporar las copia mecanografiadas de algunos de los documentos relacionados con el expediente abierto a Martí Esteve por el delito de "rebelión militar" en 1934-1935 (en relación con los hechos del 6 de octubre), los primeros informes oficiales pedidos por el juez instructor de responsabilidades políticas eran decepcionantes. Solamente, el Instituto Municipal de Estadística, de Barcelona, pudo precisar que Martí Esteve habia militado en Acció Catalana, fue «uno de los elementos más activos del gobierno rojo-separatista", marchó a Francia a comprar armas y, en definitiva, se le podía considerar "persona en extremo peligrosa para el Movimiento Nacional» ${ }^{16}$. Éste era ya un buen comienzo.

Al igual que Ventura Gassol, en el expediente de Martí Esteve la policia barcelonesa fue más allá y respondió plenamente a las expectativas creadas. Si con Ventura Gassol, las informaciones policíacas habían alcanzado cotas importantes, con Martí Esteve se superaron:

La actuación de este maléfico sujeto en la política catalana y en el período marxista se puede definir resumiendo, como una de los más eficaces colaboradores pro-causa rojo-separatista y por ende de los más tenazmente opuestos al triunfo de las armas Nacionales. Al servicio de este programa puso su inteligencia y asi como hubo bandidos que se dedicaron al pillonaje [sic] de barrio y de particulares para allegar recursos a la C.N.T.F.A.I.; éste desempeñó el mismo cargo oficialmente buscando medios y resortes con que aplastar a los que llamaban «facciosos".

Con anterioridad al G.M.N. en 1921, se salió de la Lliga pasando a formar parte y fundar el llamado Partido "Acción Catalana" de tendencia separatista.

En 1934 tomó parte muy activa en los sucesos llamados del 6 de octubre siendo condenado por el Tribunal de Garantías Constitucionales a reclusión perpetua, saliendo de la Cárcel al triunfar el Frente Popular, que le amnistió, pasando a ocupar el cargo de Consejero de Hacienda. Al incorporarse en el cargo hizo verdaderas atrocidades administrativas como abono de haberes imaginarios al nefasto Pérez Salas, a Salas Ginestar, al comandante Bosch, a los demás comandantes Guarnel [por Guarner] y Gómez García y demás militares que sufrieron condena por los hechos arriba citados, asi como abono de indemnizaciones irreglamentarias a todos los separatistas que por aquellos hechos estuvieron en la Cárcel. Entrando de lleno en los hechos del 18 de

16 En referencia al patrimoni personal del inculpado, los funcionarios municipales no habian localizado nada en Barcelona, upero se tiene la certeza de que posee fincas en el pueblo de Torá (Lérida)". Por contra, la policia barcelonesa parecía estar muy enterada de los negocios y la fortuna económica de Martí Esteve: “[...] lo que afecta a sus bienes de fortuna es incrementada por los robos y los saqueos de la primera época, pudiendo calificarse de fabulosa; si bien la que se le conocia es dificil de precisar por figurar a nombre de tercera persona, como él mismo afirmó al salir de presidio, que "convencido del Alzamiento Nacional iba a poner los bienes a nombre de su mujer", pudiendo otros complicados en las Cámaras y Bancos que oculten sus fincas y rentas, pues él fue muchos años asesor de la Cámara Mercantil...". 
julio de 1936, se ha de significar [...] que fue el hombre que puso toda su inteligencia al servicio de la maldad, cabiéndole el [?] de saquear la Banca de Barcelona, ordenando la entrega del contenido de las Cajas de alquileres de Bancos de valores extranjeros, como joyas y objetos de arte, tomó parte en la Comisión de Compras de Guerra para el Ejército Rojo, efectuando continuos viajes a Francia de la que no regresó en uno de ellos. Durante el tiempo que vivió en Barcelona llevó una vida opulenta y regalada cuidando de acumular medios para continuarla en el extranjero, teniendo para ello especial cuidado de seleccionar de entre los bienes del Estado y de los demás todo lo cotizable fuera de España ${ }^{17}$. En su permanencia en la extinguida Generalidad obró a su antojo gobernando a su capricho y sin necesidad de acuerdos con de Gobierno, sumando la respetable cantidad de 90.000 .000 de pesetas las que había [?] los primeres meses a la revolución procedentes del Banco de España de que se incautó la Generalidad y que dirigió Carrasco y Formiguera ajusticiado en la España Nacional con ocasión de ser apresado el mar Cantábrico [sic]...

Probablemente, se trata de uno de los informes más duros que emitió la policía barcelonesa contra un dirigente republicano. La mezcla de dinero, militancia política y cargos de responsabilidad parecía que les había puesto especialmente nerviosos. En el informe policíaco había poca argumentación política y muchas insinuaciones acerca de «ingeniería financiera" de la época. No dejaba de ser significativo el interés mostrado por los pagos que Martí Esteve habría hecho a diferentes represaliados por los hechos de octubre de 1934; un interés mucho mayor que no el demostrado por conocer el papel político de Martí Esteve en aquel episodio. Tampoco no era gratuita la alusión a la confiscación del Banco de España en Barcelona al empezar la guerra. Como en la cuestión del patrimonio artístico, el dinero era un asunto muy delicado y sensible para las autoridades franquistas.

Era difícil que nadie superase los niveles de demagogia conseguidos por la policia barcelonesa. De hecho, a su lado los informes de Falange recibidos por el juez instructor era casi inocuos. Si limitaban a constatar que Martí Esteve militaba en el partido catalanista (en el segundo informe falangista se corregía: partido separatista) Acció Catalana; también se le consideraba «uno de los responsables de la situación caótica reinante en

\footnotetext{
17 Aunque se refieran a dos etapas cronológicas distintas, hay un fondo común en la narración de la policía y las noticias de la prensa del invierno de 1939. Por ejemplo, La Vanguardia Española ("Agonía de la guerra. La huída de los rojos derrotados toma carácter de un enorme desastre", 30-1-39): "Constantemente atraviesan la frontera francoespañola gran número de camiones conteniendo cuadros, muebles, etc., producto de robos cometidos por los dirigentes rojos, y con cuya venta se proponen reunir un capital que les permita vivir con lujo en el extranjero. Estas expediciones son las iniciales de los despojos realizados, porque, a no dudar, seguirán otras nuevas...". En la misma línea, el artículo de Fernando Ors, "Saqueo, robo, contrabando, negocios, comisiones. Ésta ha sido la táctica invariable de los directivos rojos" (La Vanguardia Española, 11-II-39).
} 
España con anterioridad al 19 de julio de 1936»; juzgado por los hechos de octubre de 1934, regresó al cargo de Consejero de la Generalitat después del triunfo del Frente Popular. En agosto de 1936 marchó a Francia con su mujer e hijos. Antes «desfalcó una fuerte cantidad de dinero». En París «continuó sus actividades contra el Glorioso Movimiento, actuando como representante de la "Generalidad" en la capital francesa".

Poca cosa más se añadió al expediente de responsabilidades políticas. El juez instructor decidió cerrarlo en este punto y en su resumen preceptivo recogió lo más importante de los informes oficiales y añadió algún comentario de su cosecha particular. Como era de esperar, la sentencia del Tribunal Regional declaraba responsable político a Martí Esteve y le aplicaba las sanciones máximas, incluyendo la propuesta de retirada de la nacionalidad española. La factura que estaban pagando los antiguos consejeros de la Generalitat implicados en los hechos del 6 de octubre de 1934 era muy elevada.

Detrás de Martí Esteve, le tocó el turno al ex-Consejero de Trabajo, Martí Barrera i Maresma. El suyo era un expediente rico en detalles, en la medida que su trayectoria política había estado vinculada a sectores obreristas y catalanistas, lo que permitía a las autoridades franquistas tener una perspectiva particularmente rica (demagógicamente rica) del personaje. Con Martí Barrera podia construirse un retrato que, partiendo de la combinación clásica «rojo-separatista», iría añadiendo otros elementos no menos clásicos del imaginario franquista: la masonería, el anarquismo, el sindicalismo...

Los primeros papeles en llegar al juzgado de instrucción de responsabilidades políticas fueron las copias de las fichas policiales referentes a los hechos de octubre de 1934, por los que Martí Barrera había sido condenado a treinta años de prisión (como el resto del gobierno catalán del momento). Perfectamente establecido este primer punto, el expediente empezaba a llenarse de contenidos con el informe de la Guardia Civil; al contrario que en los casos anteriores, en éste la Benemérita tenia bastantes cosas por decir:

[...] Hombre sin escrúpulos de ninguna clase, ingresó en la masonería en la logia "Resurrección" con el grado $3^{\circ}{ }^{18}$; simpatizante con los anarquistas administró durante algún tiempo "Solidaridad Obrera".

18 El 10 de junio de 1940, la Delegación del Estado para la Recuperación de Documentos de Salamanca, encargada de clasificar el enorme botín de guerra conseguido con la confiscación de archivos públicos (entre ellos, los de la Generalitat) y privados (por ejemplo, papeles y la biblioteca del dirigente republicano catalán Antoni Rovira i Virgili), para su uso policial, contestó al juez instructor que no había tenido tiempo de comprobar si Marti Barrera era efectivamente masón. 
Colaboró mucho con Jaime Aguadé Miró ${ }^{19}$, elemento separatista e influido por este hizo gran propaganda entre las masas obreras de la C.N.T. y F.A.I. para que defendieran el programa de Maciá y de la Esquerra Republicana. Desde tiempo de la Dictadura del General Primo de Rivera, corrió todas sus aventuras políticas junto con Aguadé. Martín Barrera, gran hipócrita, guardaba las apariencias de gran burgués mostrando recibos de la contribución Industrial que pagaba y protestando que le tratasen como un revelde [sic].

[...] tuvo gran concomitancia con Francisco Layret ${ }^{20}$ y junto a éste hizo mucha campaña separatista. Masón desde el 1923 pasó de la Logia Gran Oriente a la Gran Logia Española; estuvo a las órdenes de Portela Balladades [sic] y de acuerdo con él llevó a muchos anarquistas a las filas marxistas. A principios del año 1931 hizo este individuo una enorme campaña de propaganda revolucionaria en la que gastó unos 6.000 duros y a fines de que se saciera [por resarciera] de la cantidad invertida y como premio a su labor fue incluido en la candidatura de Diputados del Parlamento de la Generalidad y por su gran amistad con Aguadé, obtuvó la Consejería de Trabajo.

En 1934 este individuo quitó de su nombre la Imprenta "Litografía Posmos [por Cosmos]" y la puso a nombre de Juan García Machín su socio, esto lo hizo con el fin de eludir responsabilidades pues en dicha imprenta se hacian muchas publicaciones de carácter separatista, anarquista, etc.

Este individuo siempre se comportó criminalmente [?] lo que significaba España además esquilmó a cuantos pudo, robando y estafando huyó y se le supone en Francia.

La Guardia Civil había encontrado - y expuesto- todos los elementos que formaban parte del discurso franquista: masonería, anarquismo, separatismo, dinero y oscuros negocios, etc. ${ }^{21}$. Además, el informe de la Benemérita marcaría la pauta de los que vendrían después. En este sentido, el expediente de Martí Barrera era uno de los más coherentes y bien acabados.

19 Uno de los dirigentes más importantes de Esquerra Republicana, alcalde de Barcelona entre 1931 y 1933 y ministro de diferentes gobiernos de la República. Padeció dos expedientes de responsabilidades políticas, uno en Barcelona y el otro en Madrid. La sentencia se dictó en el Tribunal Regional de Barcelona.

20 Abogado laborista destacado a principios de los años veinte, fue asesinado por pistoleros de la patronal barcelonesa en el contexto de los años del pistolerismo y los enfrentamientos a sangre y fuego entre patronal y sindicalistas en Barcelona.

21 Sólo faltaba el elemento antisemita (que si está presente, de forma solapada, en algunos expedientes contra dirigentes de Lliga Catalana, por ejemplo), que puede encontrarse en algunos de los artículos de prensa más antológicos de la guerra. Es el caso de Juan Pujol ( Cuando Israel manda", $A B C$, Sevilla, 20-XII-36) quien optaba por el menosprecio directo ("Judio es Companys -descendiente de judíos conversos y no hay más que verle la jeta para comprenderlo..."); o es el caso de Luis Antonio de Vega ( «Roble y Acacia. El regionalismo en los Protocolos de Sión", Domingo, 13-11-38), autor de una teoría delirante, sin pies ni cabeza, que vinculaba la famosa conspiración judía mundial y Esquerra Republicana de Cataluña. Ambos textos en Josep Benet, op. cit., pp. 120-122. 
El informe del ayuntamiento de Barcelona no decía gran cosa; reseñaba las militancias políticas y sindicales de Martí Barrera y los cargos que habia ocupado, pero no iba más lejos. Por contra, el de la policia barcelonesa era una explosión de datos, informaciones, comentarios, rumores, etc. Era paralelo y, a la vez, complementario del de la Guardia Civil:

[...] el informado, aprovechando el período álgido de los sindicatos, de simple obrero de una fábrica de fideos, propiedad de la viuda de Lligonia, establecida en la calle de S. León, pasó a la administración del diario anarquista "Solidaridad Obrera" por el año 1922, de donde tuvo que salir por no presentar la contabilidad en regla, en el referido cargo, conoció al impresor Francisco Gasque y a Juan García Machín, fundando la tipografia "Cosmo", donde se publicó la propaganda anarquista, Vida Sindical, Vida Ferroviaria y el diario "La Batalla". Más tarde conoció al nefasto Jaime Aguadé Miró, de quien publicó las Monografías Médicas, de tendencia totalmente separatistas a pesar de su requerida presentación científica, con el fin de conseguir que las masas obreras sugestionadas y enardecidas de morboso espíritu gregario pertenecientes a la C.N.T.F.A.I. Ilegasen a defender las fatidicas locuras de Masiá [sic] y Companys. Ingresó en la masonería en el año 1922, ignorándose a la Logia que pertenecía y las actividades que en ella desarrolló, y en ocasión de estar a las órdenes de Portela Valladares por razones de negocio, el citado Portela obtuvo precisamente por el informado el alistamiento de anarquistas pistoleros a las filas masónicas, formando un grupo de treinta individuos [...] más tarde formó con los supervivientes el famoso "Grupo de los treinta" con el líder Ángel Pestaña, siendo los primeros pasos del partido sindicalista, a raíz de los cual se publicó un manifiesto titulado "De los treinta». Por carecer de escrúpulos se relacionaba con la crápula sociedad debido a su gran egoismo por el dinero careciendo de ideología sana y definida, prueba de lo cual son las referencias que hay en su complicidad con el escandaloso atraco al tren de $\mathrm{Ba}$ dalona en Pueblo Nuevo.

Al fundarse la Esquerra Republicana de Catalunya, pasóse a ella, con vistas al campo abonado que allí existía para sus andanzas, y con el advenimiento de la nefasta república imprimió tota la propaganda izquierdista importe que ascendía a más de setenta mil pesetas, no haciéndoselas efectivas la C.N.T. ni en parte los republicanos federales, por cuyo motivo le retiró el crédito La Papelera Española, por estas circunstancias y con el fin de que se resarciera de la gastada cantidad fue incluido en la candidatura a diputado del aciago parlamento de la Generalidad debido a su gran amistad con Aiguadé obtuvo la consejería de Trabajo. También perteneció al partido Republicano [Radical?] aunque poco tiempo. El cargo de consejero de trabajo lo obstentó [sic] desde la aprobación del estatuto hasta octubre del 34 que fue detenido y encarcelado como cómplice de la intentona revolucionaria rojo-separatista; y desde febrero de 1936 hasta los primeros meses del Glorioso Alzamiento Nacional, siendo además durante el mismo como hombre de confianza el presidente del llamado Tribunal de Responsabilidades Políticas. Al ser liberada esta capital huyó con dirección a Francia. 
¿Qué más podía decirse con un informe tan sangrante y delirante como éste? Era el lenguaje del vencedor en estado puro. Martí Barrera les habia ofrecido la posibilidad de dar un repaso a todos los tópicos políticos e ideológicos que los franquistas habían incorporado a su discurso. Junto a estos tópicos, añadían rumores y comentarios malévolos acerca de la integridad moral y personal del inculpado, que iban mucho más allá de la pura argumentación política que utilizaba la máquina de la represión -y de la propaganda - de los vencedores. Era una progresión constante de los niveles de violencia verbal, alimentados permanentemente desde, como mínimo, el año 1936, por dirigentes políticos, civiles, militares, periodistas, escritores, funcionarios, eclesiásticos, etc., que tenían muy claro por qué habian provocado una sublevación y cual era el precio que querían hacer pagar a los vencidos. No era solamente un asunto de unos policías de Barcelona, especialmente predispuestos contra los dirigentes republicanos catalanes y todos los representantes de la combinación «rojo-separatista»; los funcionarios de la Jefatura Superior de Policía de Barcelona no se habían inventado el lenguaje, las expresiones ya hechas, los adjetivos. Lo habian aprendido, asimilado y reciclado a partir de una inmersión permanente en los fondos más pútridos de la propaganda oficial franquista, en la literatura españolista y derechista más rancia, vulgar y extremista, en los discursos de la extrema derecha más violenta. Los policías que escribían los informes -como los falangistas, los guardias civiles o los funcionarios municipales - representaban la culminación del discurso, pero no eran sus autores ${ }^{22}$. Como piezas básicas de un Nuevo Estado nacido de la violencia armada, su violencia verbal era una parte más de los fundamentos ideológicos sobre los que el franquismo quería legitimarse y justificar el acto de traición fundacional a la legitimidad republicana.

La demagogia desbocada de la policia barcelonesa — precedida por la de la Guardia Civil- contrastaba con el informe falangista, mucho más ecuánime y contenido. Los falangistas se permitían pocos excesos verbales, más allá de los tópicos acerca de "la nefasta República», "los luctuosos sucesos revolucionarios del 6 de octubre de 1934", etc. Incluso, al final del informe, se reconocía que Martí Barrera «al parecer, salvó a algunas personas, evitando que

22 Conxita Mir, Fabià Corretgé, Judit Forné, Joan Sagués, Repressió econòmica i tranquisme..., pp. 211-216, son muy precisos en sus conclusiones: "L'ús d'aquest llenguatge té uns objectius molt clars. Dins un context repressiu, que aspirava a esborrar totalment qualsevol vestigi de resistència i a derrotar absolutament i definitivament els vençuts, la repetició constant, i en tots els àmbits, d'aquests estereotipus contribueixen decididament a configurar una memòria col-lectiva de les etapes anteriors notòriament desfigurada. En aquest llenguatge no podem buscar una descripció dels fets històrics fidel a la realitat, ans, intencionadament, es reflecteix la visió de la República i la guerra que en tenien els vencedors. Es legitima aixi l'atac contra la República, la brutal repressió dels vençuts, i es justifica ideológicament el Nou Estat» (cita en la p. 214). 
fueran asesinadas por las hordas". El repaso al historial político del inculpado era bastante ajustado a la realidad: no había atracos a trenes, ni problemas de contabilidad empresarial. En este sentido, era un informe claro y conciso.

El juez instructor cerró el expediente en este punto. Evidentemente, Martí Barrera era responsable político -implicado en nueve apartados del artículo $4^{\circ}$ de la Ley-y el juez se cuidó muy mucho de no incorporar a su resumen el comentario falangista acerca del salvamento de gentes de derecha en el verano de 1936.

La sentencia del Tribunal Regional estaba en línea con el contenido del expediente. Sólo había un matiz en relación a sus compañeros del Gobierno de la Generalitat: las sanciones eran las máximas previstas, pero no se incluyó la propuesta de retirarle la nacionalidad española.

El último personaje de este grupo de ex-Consejeros de la Generalitat era Joan Comorera, secretario general del PSUC. En su caso, el interés estaba centrado - además de en los cargos habituales- en el hecho de que se trataba de un comunista de una pieza. Si los otros consejeros venían de la tradición republicana catalana, Comorera era un veterano militante socialista que, en 1936, dio el paso decisivo con el liderazgo del proceso de unificación de las fuerzas comunistas/socialistas que dio lugar al nacimiento del PSUC. Aquí, el franquismo no estaba obligado a establecer asociaciones extrañas, ni buscar explicaciones extravagantes para hacer coincidir las dos partes de la ecuación "rojo-separatista". Desde la óptica de los vencedores, Joan Comorera reunía las dos características de forma casi perfecta, sin la necesidad de forzar los razonamientos. La policia barcelonesa lo había sintetizado en un párrafo algo confuso pero significativo: «Al proclamarse la funesta República en España, regresó a Barcelona, ingresando en la Unión Socialista de Cataluña que actuaba independiente del Partido Socialista Español [sic] debido a su matiz catalanista. Pronto fue la figura destacada de dicho organismo, que contaba con escasísimas fuerzas en Cataluña, y únicamente gracias al apoyo que le proporcionó la Esquerra pudo obtener puestos representativos en el Ayuntamiento, Generalidad, Parlamento Catalán e incluso en las Cortes. Intentaron varias veces unirse con el Partido Socialista Español, dificultando tal fusión el aspecto particularista de separatista, además de Socialista. Durante el dominio rojo-separatista se transformó en el P.S.U.C. adherido a la Internacional Comunista» ${ }^{23}$.

23 En el informe de la policia habia otros comentarios interesantes: Comorera era un «individuo de malos antecedentes", un «destacado anti-español, egoista y ambicioso", complicado "en la criminal revolución socialista de octubre de 1934». En la parte final del informe, la policia recordaba que también debía considerársele "uno de los principales culpables de los crimenes, 
Quedaban más cosas por decir. La Guardia Civil, por ejemplo, además de recordar el historial político explicaba que Comorera, en persona, se hizo cargo de la confiscación de la Compañía Trasatlántica al inicio de la guerra. Los falangistas eran un poco más generosos en su información. Joan Comorera era un "gran agitador" y uno "de los principales elementos que contribuyeron a crear el ambiente revolucionario que precedió a la iniciación del G.M.N.». Con la guerra ya empezada, se convirtió en "uno de los responsables de la resistencia roja y de los asesinatos y desmanes cometidos en esta zona durante el triste tiempo de su dominación".

Coherentes con los otros informes, el ayuntamiento de Barcelona hablaba de un personaje conocido "por sus ideas comunistas y separatistas. Una de las más destacadas figuras catalanas de la situación roja... Pertenecía al "Partit Socialista Unificat de Catalunya", siendo peligroso por sus actos, pues sembró el terror por toda la España que no tuvo la suerte de quedar en la Zona Nacional»».

Las sanciones establecidas por el Tribunal Regional fueron las máximas previstas por la Ley de Responsabilidades Políticas, incluyendo al propuesta de retirarle la nacionalidad española. Habían situado a Joan Comorera, comunista a ultranza, al mismo nivel que los republicanos catalanistas Ventura Gassol o Martí Esteve. La combinación «rojo-separatista" tomaba su sentido pleno.

Con el recuerdo de los hechos de octubre de 1934 como nexo de unión entre políticos de distinto origen e ideología, el franquismo acababa de sancionar a un grupo de personajes muy significativos del universo político e ideológico de la Cataluña de los años treinta. Manuel Aznar, el periodista y director de La Vanguardia Española en las primeras semanas de 1939, pensando en el conjunto de la sociedad catalana, había escrito que "los catalanes deben pensar seriamente que les llega el momento de cumplir inexorablemente su deber de españoles" ${ }^{24}$. Entre estos catalanes estaban los "rojo-separatistas" que tenian que pagar «inexorablemente" por supuestos delitos cometidos un 6 de octubre de 1934; y los tenían que pagar a unos españoles que, a sangre y fuego, habían liquidado toda forma de «rojerío" y de separatismo.

robos, saqueos y desmanes cometidos por las hordas, tendiendo en sus propagandas y mítines a excitar el ánimo de las gentes denunciando él mismo públicamente a personas simpatizantes con la Causa Nacional..."

${ }^{24}$ Citado por Josep Benet, op. cit., p. 195. 